\title{
Vulnerabilidade costeira a partir da abordagem multicritério: estudo de caso no litoral sul do Espírito Santo
}

\section{Multicriteria approach on coastal vulnerability: a case study on the southern coast of Espírito Santo}

\author{
Gilberto Daniel Lima Filgueiras* $\varangle(\mathbb{D}$, Jacqueline Albino $\triangle(\mathbb{D}$ \\ Universidade Federal do Espírito Santo, Vitória, Espírito Santo, Brasil \\ E-mails: albino.jacqueline@gmail.com \\ *E-mail para correspondência: gilberto.lima94@gmail.com
}

Recebido (Received): 20/01/2020

Aceito (Accepted): 27/07/2020

\begin{abstract}
Resumo: Questões relacionadas à vulnerabilidade costeira têm importância ao longo de todo mundo, devido às questões climáticas, elevação do nível dos oceanos e expansão urbana sobre tais regiões. Faz-se, necessário entender o grau de vulnerabilidade costeira e os fatores envolvidos, com o intuito de evitar perdas socioeconômicas e também ambientais. $\mathrm{O}$ presente estudo objetivou analisar, mediante o Índice de Vulnerabilidade Costeira (CVI), de que modo a vulnerabilidade costeira é alterada com a mudança das características ao longo da costa dos municípios de Marataízes e Presidente Kennedy, localizados no litoral sul do estado do Espírito Santo. Geomorfologia costeira, Modelo digital de elevação, taxas de mobilidade costeira e distância da isóbata de $20 \mathrm{~m}$, foram obtidas por meio de dados de sensoriamento remoto. A espacialização e integração dos dados mediante o CVI foi efetuado com utilização de software GIS. Os resultados mostram que em $49 \%$ dos $44 \mathrm{~km}$ do litoral a vulnerabilidade é moderada a muito alta, com ênfase para as regiões do litoral com existência de falésias e extensas planícies costeiras. Discute-se diferentes formas de ação para minimizar prejuízos frente ao processo de futura urbanização e as diferenças entre as ações a serem tomadas pelos municípios de Marataízes e Presidente Kennedy, que possuem padrões de urbanização contrastantes. Conclui-se que o conjunto de dados de sensoriamento remoto se mostrou eficaz na determinação da vulnerabilidade costeira e que as questões relacionadas às mudanças climáticas devem começar a serem enfrentadas sob a ótica de longo prazo.
\end{abstract}

Palavras-chave: Mudanças climáticas; Risco costeiro; Índice de vulnerabilidade costeira; Smartline.

Abstract: In recent decades, problems related to coastal vulnerability have been important on the coasts of the world due to climatic issues, rising sea level and urban growth in these regions. The degree of coastal vulnerability and the factors involved in order to control socioeconomic and environmental hazards has been a fundamental study. This study analyzes, through the Coastal Vulnerability Index (CVI), how coastal vulnerability is altered with changing characteristics along the coast of the Marataizes and Presidente Kennedy cities, south of the of Espirito Santo coast. Geomorphology, digital elevation model, coastal mobility rates and $20 \mathrm{~m}$ isobath distance, which reflect the degree of wave exposure, were obtained through free remote sensing data. Data spatialization and data integration using CVI was performed using GIS. The coastal vulnerability is moderate to very high in $49 \%$ of the $44 \mathrm{~km}$ studied coast, especially the coastal regions with the presence of bluffs and extensive coastal plains. Different forms of action have been considered to the process of future urbanization and differences between the actions to be taken by the citizens of Marataizes and President Kennedy, which have contrasting urbanization patterns. To close, the remote sensing dataset proved to be effective in determining coastal vulnerability and that climatic change issues should begin to be addressed from a long term perspective.

Keywords: Climate change; Coastal risk. Coastal vulnerability index; Smartline. 


\section{Introdução}

Os sistemas costeiros são complexos e variáveis em amplas escalas espaciais e temporais (BOAK; TURNER, 2005). Os processos costeiros atuantes nem sempre podem ser descritos pelas leis básicas da física, pois a multiplicidade de componentes, alguns dificilmente previsíveis, interagem dinamicamente ao longo de uma superfície altamente interconectada. (BOAK; TURNER, 2005; BONETTI; WOODROFFE, 2017). Pode-se esperar então que, as áreas costeiras experimentem regularmente perturbações no seu estado de equilíbrio, ajustando continuamente a sua morfologia para condições dinâmicas recentemente impostas (WOODROFFE, 2002).

O comportamento de muitos sistemas naturais pode ser visto como cíclico e, geralmente, oscila através de um estado de maior ou menor equilíbrio dinâmico. Em contraste, a exposição de bens humanos a riscos costeiros tende a resultar em mudanças e danos mais permanentes e lineares (BONETTI; WOODROFFE, 2017). Em áreas urbanizadas, esses impactos ocorrem principalmente por uso e ocupação da terra de forma irregular, desrespeitando faixas naturais de mobilidade exigidas pelos ambientes (ALBINO et al., 2001; BOATENG, 2012; YIN et al., 2012; HEREHER, 2015).

A estimativa de um aumento no nível do mar de até $82 \mathrm{~cm}$ para 2100 (CHURCH et al., 2013) converge para a maior atenção na vulnerabilidade da zona costeira frente aos cenários previstos. Logo, são necessários estudos que levam à compreensão dessa faixa de interação entre os ambientes continental e oceânico, bem como sua gestão e utilização de forma efetiva e segura.

O significativo aumento do nível do mar é estimado em decorrência do aquecimento global intensificado pelo homem durante o século 21 (NICHOLLS; LOWE, 2004) confronta simultaneamente, o fato que as populações costeiras estão crescendo mais rápido do que a população global, logo as cidades costeiras devem se tornar o principal cenário de habitação para a população durante o século 21 (NICHOLLS, 1995). No caso de populações mais pobres, as ocupações irregulares e em locais menos seguros das cidades são mais sujeitas a inundações (DEVINE, 1992). Segundo Nicholls (1995), o padrão descrito por Devine (1992), de intensificação urbana em regiões costeiras mais suscetíveis, deve continuar. A magnitude dos impactos das inundações também está ligada aos cenários socioeconômicos, e diferentes formas de desenvolvimento resultam em regiões com diferentes níveis de vulnerabilidade à elevação do nível do mar e às mudanças climáticas (NICHOLLS; LOWE, 2004).

O Índice de Vulnerabilidade Costeira (CVI) é um dos mais simples e comuns métodos usados em todo mundo para determinar a vulnerabilidade costeira a elevação do nível do mar (BONETTI, 2017). Variáveis chaves são incorporadas a uma equação para produzir um valor numérico de CVI, que reflete a severidade de vários efeitos da elevação do nível do mar e destaca regiões onde isso deve ser mais crítico. Essas variáveis são ranqueadas em escala linear em ordem de incremento de vulnerabilidade a elevação do nível do mar (KLEIN; NICHOLLS, 1999). Segundo Bonetti (2017), as variáveis chaves, que tem a capacidade de moldar a evolução e a vulnerabilidade costeira originalmente propostas por Gornitz (1991), são: a geomorfologia, a taxa de variação da linha de costa, a inclinação da face costeira, a taxa de variação relativa do nível do mar, a altura máxima de onda e a amplitude de maré. Tal Índice de Vulnerabilidade Costeira tem sido aplicado com sucesso para determinar a vulnerabilidade ao longo de regiões costeiras de diferentes países como Estados Unidos (PENDLETON et al., 2005; THEILER; HAMMAR-KLOSE, 2000), Itália (PANTUSA et al., 2018), Índia (KUMAR et al., 2010), Egito (HEREHER, 2013; HEREHER, 2015), Turquia (OZYURT; ERGIN, 2010), Indonésia (LOINENAK; HARTOKO, 2015), China (YIN et al., 2012) e Brasil (SERAFIM et al., 2018).

O litoral sul do estado do Espírito Santo, formados pelos municípios de Marataízes e Presidente Kennedy, possui considerável diversidade geomorfológica em contato com o mar, dentre elas grandes planícies costeiras, falésias vivas, estreitas planícies quaternárias e afloramentos cristalinos (MARTIN et al., 1996; ALBINO et al., 2016 e ELFRINK et al., 2006). Um estudo preliminar evidenciou na mesma região que a mobilidade costeira é diretamente ligada a unidade geomorfológica presente no litoral e que é possível compartimentar tal mobilidade costeira juntamente com os compartimentos geomorfológicos ao longo do litoral.

Essa região foi apontada pela Agência Nacional de Transportes Aquaviários - ANTAQ (2009) como prioritária para a instalação portuária, no centro da costa brasileira, próxima aos grandes centros produtores e dos principais campos de petróleo e gás do país, destacando-se como um eficiente ponto para a movimentação e estocagem de petróleo e apoio offshore (Porto Central, 2018). Segundo Anfuso e Del Pozo (2009) as costas são muito afetadas por estruturas humanas, diminuindo a circulação de sedimentos com o aumento da proteção da costa e consequentemente diminuem as taxas de erosão. Contudo os processos de acréscimo são sempre evidentes à barlamar das estruturas enquanto os processos de erosão predominam na 
direção do transporte do sedimento, à sotamar das estruturas; sendo este um padrão muito comum em áreas de marinas e portos.

Neste contexto, classificar a vulnerabilidade de diferentes setores costeiros aos efeitos da subida do nível do mar é um importante passo para uma gestão eficaz da zona costeira e pode auxiliar na apresentação de algumas sugestões para tomadores de decisão e demais interessados no desenvolvimento de políticas públicas adequadas, assim como adoção de medidas de mitigação aos potenciais riscos (YIN et al., 2012).

O presente estudo objetiva determinar a vulnerabilidade costeira do litoral sul do estado do Espírito Santo, por meio de dados de sensoriamento remoto, destacando segmentos do litoral onde a vulnerabilidade apresenta-se mais elevada. Simultaneamente também objetiva-se realizar trabalhos de campo para validar eficácia do método e dos dados utilizados. Os resultados foram analisados no contexto da atual urbanização, a fim de discutir medidas para se evitar futuros riscos sócio econômicos e prejuízos que possam ser desencadeados através das forçantes meteoceanográficas e suas interações junto a costa.

\section{Metodologia}

\section{1 Área de estudo}

O setor sul do estado do Espírito Santo, formado pelos municípios de Marataízes e Presidente Kennedy (Figura 1), é dominado por depósitos quaternários pouco desenvolvidos ao sopé das falésias vivas, desenvolvidas pela ação marinha nos tabuleiros terciários do Grupo Barreiras. Por outro lado, os depósitos quaternários possuem uma considerável extensão dentro dos grandes vales escavados nos depósitos do Grupo Barreiras (MARTIN et al., 1996), (Figura 2). À exceção, associada à foz do Rio Itabapoana, onde existe a presença de extensa planície quaternária formada por sedimentos flúvio-marinhos (ALBINO et al., 2006; CONTTI NETO et al., 2011 e ALBINO et al., 2016). Na porção norte as estreitas praias arenosas são interrompidas por costões rochosos (ELFRINK et al., 2006). Nesse setor há o predomínio de praias dissipativas e intermediárias compostas por areias litoclásticas finas e limitadas por dunas frontais (Figura 2).

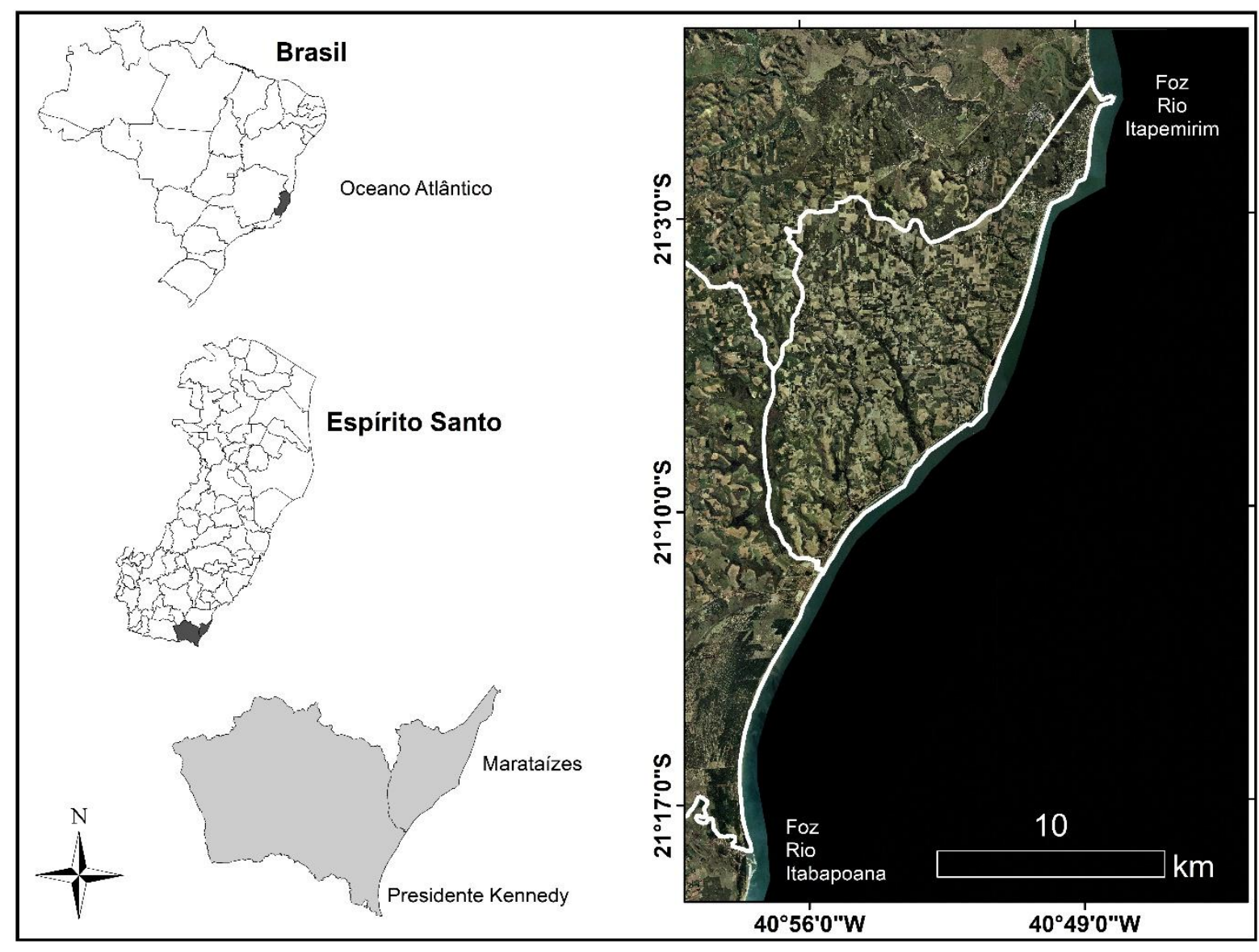

Figura 1: Área de estudo. 


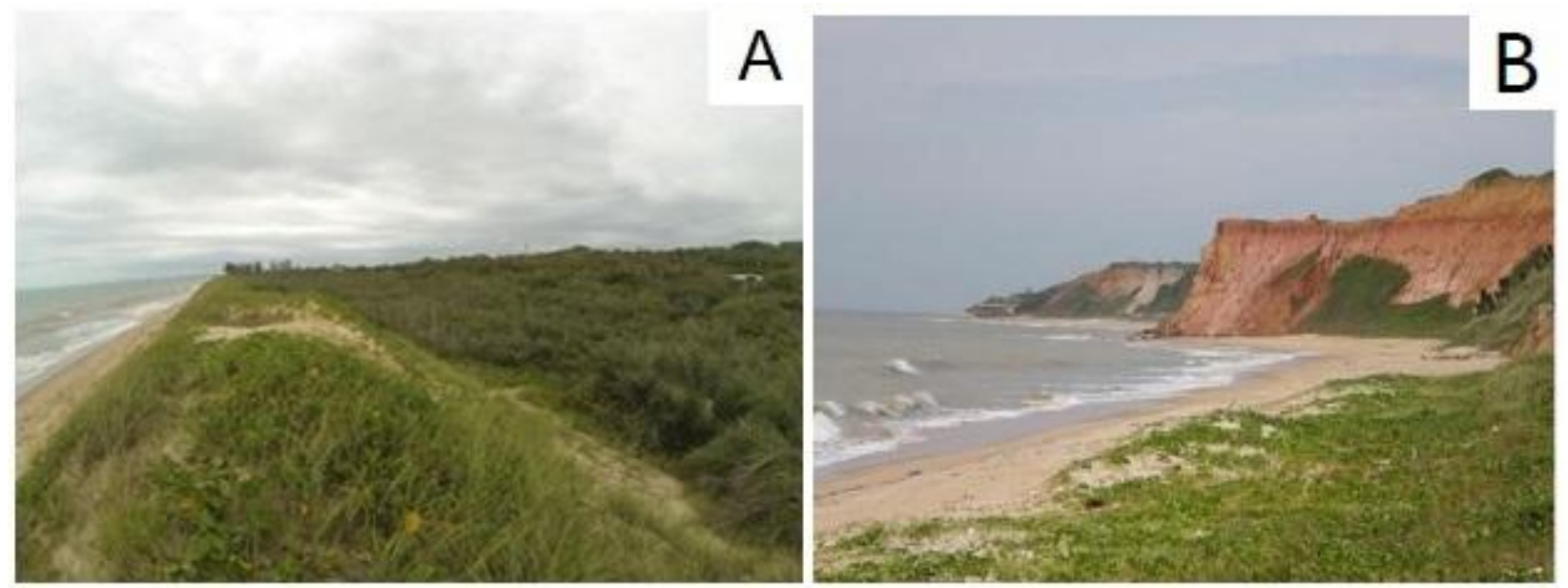

Figura 2: Em (A) Visão lateral do sistema praia-duna na Praia dos Neves, Presidente Kennedy; e em (B) Falésias sujeitas a processos erosivos por ação marinha na Praia dos Cações, Marataízes. Foto: Fernanda Pirola (A) e Jacqueline Albino (B).

Processos erosivos têm sido registrados nas últimas décadas no litoral de Marataízes onde a ocupação é mais densa (ALBINO et al., 2016). Já no município de Presidente Kennedy, a distância dos centros urbanos e o difícil acesso favorecem a preservação do sistema costeiro, que apresenta adaptação morfodinâmica regimentada a interação dos sistemas marinho e fluvial (ALBINO et al., 2006; ALBINO et al., 2016).

O litoral das cidades de Marataízes e Presidente Kennedy possuem particularidades embora a curta distância entre eles. O município de Marataízes teve seu crescimento urbano próximo a orla marítima, influenciado sob a forma de residências de veraneio, de turistas que vivem na Grande Vitória e também no estado de Minas Gerais (GIRARDI; COMETTI, 2006).

Ainda segundo Girardi e Cometti (2006), Presidente Kennedy caracteriza-se por ser predominantemente rural, sendo o único município praiano do Espírito Santo que sua sede não se localiza na orla marítima. De acordo com o IBGE (2014), Presidente Kennedy é o município com maior PIB (Produto Interno Bruto) per capta do país, de aproximadamente $\mathrm{R} \$ 815.000,00$, devido grande parte aos royalties do petróleo.

\subsection{Os critérios e variáveis}

Proposto por Gornitz (1991), o CVI (Coastal Vulnerability Index - Índice de vulnerabilidade costeira) fornece uma base numérica simples para classificar trechos da linha de costa, podendo ser aplicado para identificar locais específicos onde os riscos podem ser relativamente altos (RAMIERI et al., 2011).

As variáveis são selecionadas devido a sua representatividade de sintetizar características do litoral. Originalmente foram propostas por Gornitz (1991): Geomorfologia, taxa de variação da linha de costa, inclinação costeira, taxa de variação relativa do nível do mar, altura máxima de onda, e amplitude de maré. Tal abordagem é muito utilizada e modificada com a incorporação ou supressão de variáveis devido a necessidade de adaptação a uma região ou ainda devido a disponibilidade de dados para regiões específicas (BONETTI; WOODROFFE, 2017).

Ainda segundo Bonetti e Woodroffe (2017), após espacialização em Sistema de Informações Geográficas (SIG), cada segmento do litoral recebe um valor para vulnerabilidade em escala de 1 a 5 para cada variável espacializada, sendo o valor 1 correspondente à vulnerabilidade muito baixa e 5 a muito alta.

A vulnerabilidade é obtida após a integração desses dados para calcular um valor final do CVI para cada trecho do litoral, através da Equação 1.

$$
C V I=\sqrt{\frac{(a \times b \times c \times d)}{N}}
$$

Onde:

CVI = índice de vulnerabilidade costeira

$\mathrm{a}, \mathrm{b}, \mathrm{c}$ e d = Variáveis

$\mathrm{N}$ = Número de variáveis 
A metodologia aplicada para a utilização do CVI e a determinação da vulnerabilidade costeira segue o padrão exibido no fluxograma (Figura 3) a seguir, na qual adotou-se e escolha de 4 variáveis que serão ranqueadas individualmente em 5 classes de vulnerabilidade e posteriormente serão incorporadas ao CVI.

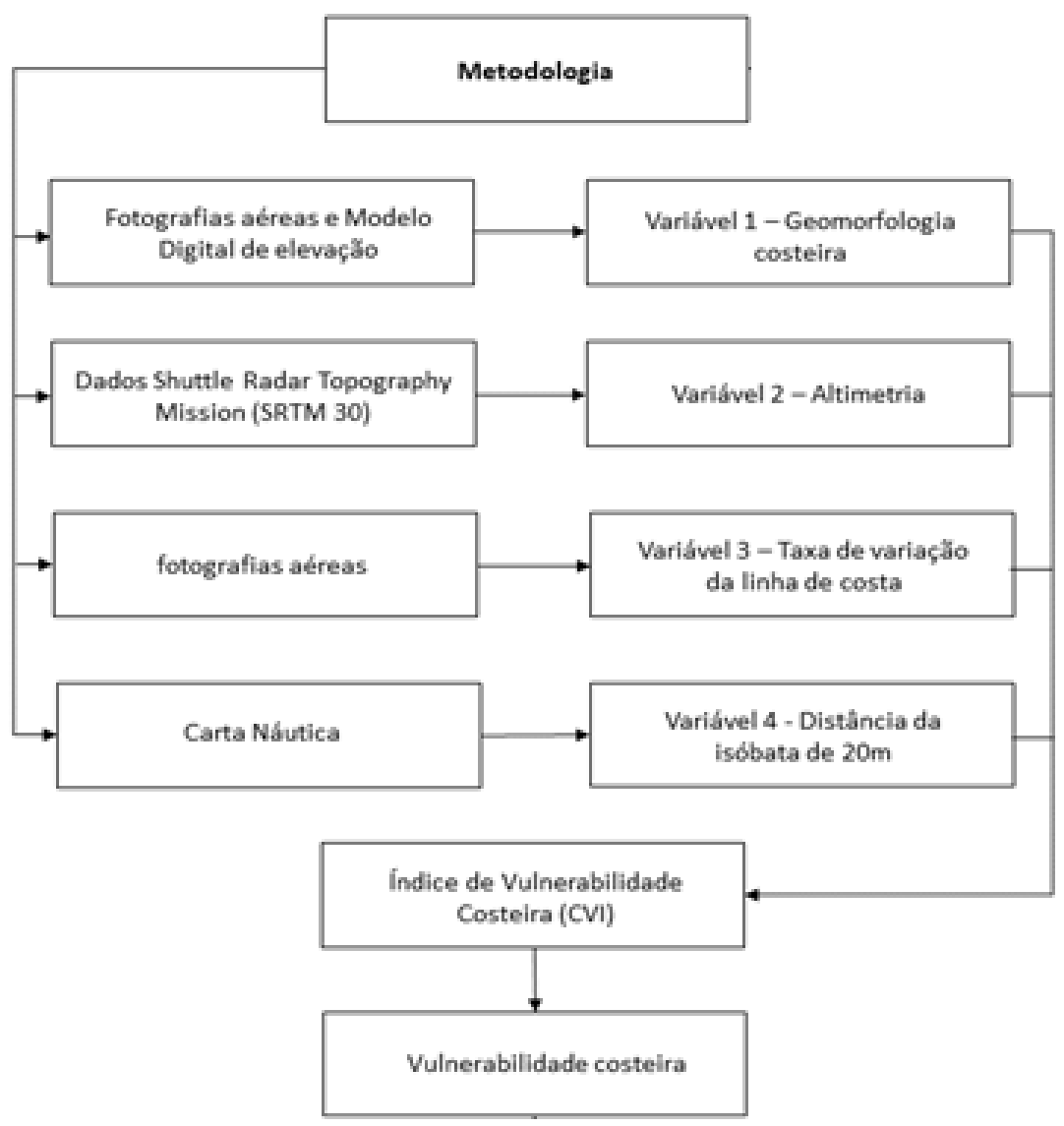

Figura 2: Fluxograma da metodologia aplicada.

Para fácil entendimento, os resultados serão mostrados sob a forma gráfica com a utilização da técnica de visualização smartline, que consiste na exibição do resultado das variáveis analisadas, assim como o resultado final num único mapa; proposta por Sharples et al. (2009) e aplicada por Pantusa et al. (2018) e Burningham e French (2017).

\subsubsection{Variável 1 geomorfologia costeira}

A Geomorfologia é a ciência que estuda a origem e desenvolvimento do relevo e da paisagem bem como a história da superfície do planeta, enquanto que a geomorfologia costeira trata das formas de relevo que ocorrerem ao longo da costa (BIRD, 2008). O relevo costeiro não apenas destaca o tipo de rocha de determinado segmento costeiro, mas também indica sua resistência contra erosão e estabilidade da costa (HEREHER, 2015).

Neste estudo, entende-se o termo "geomorfologia costeira" como sinônimo do termo "coastal landforms geomorphology" utilizado por Gornitz (1991), e de acordo com ele as formas de relevo costeiro variam substancialmente na sua resistência à erosão. A geomorfologia costeira foi interpretada visualmente a partir de fotografias aéreas e imagens de satélites (Tabela 1), e com a interpretação do modelo digital de elevação (MDE) criado a partir dos dados SRTM, com resolução espacial de 30m, adquiridos no Serviço Geológico Americano (USGS) disponível em (https://earthexplorer.usgs.gov/). A análise dessa variável seguiu a classificação de macro unidade morfológica realizada por Albino et al. (2006). Essa interpretação foi validada por consulta bibliográfica para a área de estudo através de Martin et al. (1996); Albino et al. (2006); Elfrink et al. (2006) e Albino et al. (2016). 


\subsubsection{Variável 2 altimetria}

A altimetria através do modelo digital de elevação de alta resolução (DEM), pode fornecer vantagens substanciais na previsão dos efeitos da inundação. Extensas avaliações do aumento do nível do mar exigem mapas topográficos de toda a zona costeira. O SRTM (Shuttle Radar Topography Mission), originalmente produzido pela NASA, é um bom conjunto de dados topográficos de domínio público para o mapeamento de áreas de inundação. O MDE global SRTM, com resolução horizontal de $1 \mathrm{~s}$ (aprox. $30 \mathrm{~m}$ ) e precisão vertical de $\pm 1 \mathrm{~m}$, cobre latitudes entre 60N e 56S (SANDERS, 2007).

O total de 76 perfis transversais de $1 \mathrm{~km}$ a partir da linha de costa com equidistância de $500 \mathrm{~m}$ foram construídos, interpolados com o MDE criado previamente dando origem a 76 perfis altimétricos que foram individualmente analisados através de software GIS.

\subsubsection{Variável 3 taxa de variação da linha de costa}

A análise da evolução da linha de costa foi realizada para um período de 44 anos usando 2 conjuntos de fotografias aéreas e 1 conjunto de imagens de satélite, entre os anos de 1969 e 2013 (Tabela 1).

Tabela 1: Indicador de linha de costa, resolução, fonte e DATUM de cada mosaico de imagens.

\begin{tabular}{|c|c|c|c|c|}
\hline Ano & $\begin{array}{l}\text { Indicador de linha } \\
\text { de costa }\end{array}$ & Resolução & Fonte & DATUM \\
\hline 1969 & Limite da praia* & Aproximada de $2,4 \mathrm{~m}$ & $\begin{array}{c}\text { Instituto Jones dos } \\
\text { Santos Neves }\end{array}$ & WGS1984 \\
\hline 2008 & $\begin{array}{l}\text { Limite do pós } \\
\text { praia* }\end{array}$ & Aproximada de $1,0 \mathrm{~m}$ & Geobases & WGS1984 \\
\hline 2013 & $\begin{array}{l}\text { Limite do pós } \\
\text { praia* }\end{array}$ & Aproximada de $1,2 \mathrm{~m}$ & Geobases & WGS1984 \\
\hline
\end{tabular}

O processo que permite a aquisição e análise dos dados de mobilidade da linha de costa é subdividido em 3 processos distintos: o georreferenciamento das fotografias aéreas e imagens de satélites, a extração das linhas de costa e o cálculo da mobilidade da linha de costa.

O georreferenciamento foi feito a partir metodologia descrita por Araújo et al. (2008), que relaciona o posicionamento da imagem com coordenadas reais da área por meio de pontos de controle (PC), que são feições identificadas nas imagens não possuindo deslocamentos durante o período estudado. Para servir de base foi utilizado o mosaico de imagens de satélite do ano de 2008, visto que se encontra retificada e validada com base no Padrão de Exatidão Geográfica 2 (PEC 2), facilitando a comparação dos dados gerados a partir da análise dessas imagens. Esse processo resultou num erro médio no posicionamento das imagens de 4,04m, o que em termos de taxa anual representa um erro médio de 0,09m/ano.

No processo de extração de linha de costa, segundo Boak e Turner (2005) estudos costeiros utilizam indicadores para representar a real linha de costa, caracterizada pela interface terra-água. Neste estudo foi utilizada o limite do pós-praia, como calçamento de ruas, muro de casas, linha de vegetação e base de falésias, como o indicador da real posição da linha de costa, a fim de se obter um mapa de tendência de erosão / acreção (Figura 6, linha D). As linhas foram traçadas com o auxílio de software de geoprocessamento, utilizando a mesma escala a fim de padronizar o processamento dos dados.

No cálculo de mobilidade foi utilizada a metodologia proposta por Thieler (2005) e utilizada nos estudos realizados por Muehe e Oliveira (2014), Araújo et al. (2008) e Eguchi e Albino (2018), que utiliza a extensão DSAS (Digital Shoreline Analysis System), disponível para aplicação com software GIS. O método consistiu na criação de 386 transectos à linhas de costa com espaçamento pré-definido de $100 \mathrm{~m}$. Calculou-se a distância entre as linhas de costa em cada transecto e dividiu-se essa distância pelo tempo (em anos) decorrido entre a aquisição das imagens, obtendo assim as taxas de variação da linha de costa.

\subsubsection{Variável 4 distância da isóbata de 20m}

Contrariando a situação em águas profundas, a dinâmica das ondas em águas rasas é dominada pela sua interação com o fundo. Existem diferentes mecanismos de dissipação da energia de onda no fundo, como energia dissipada pela percolação, fricção, entre outros (PADILLA-HERNÁNDEZ; MONBALIU, 2001; 
MATOS et al., 2014). O atrito de fundo parece ser o mecanismo mais importante para a dissipação de energia de ondas em regiões costeiras arenosas (SHEMDIN et al., 1978). Estudo realizado por Trombetta $e t$ al. (2018) através de modelagem numérica para a plataforma continental sul do Brasil, detectou que uma declividade mais suave, comum em plataformas mais extensas, pode reduzir em até $98 \%$ a altura das ondas que se aproximam da costa, e aproximadamente $90 \%$ do potencial energético, tendo capacidade de atenuar os efeitos erosivos causados pelas ondas na área litorânea.

No estudo foi medida a distância entre a linha de costa e a isóbata de $20 \mathrm{~m}$ de profundidade com auxílio da Carta Náutica n¹403 "Da barra do Itapemirim ao Cabo de São Tomé" disponibilizada gratuitamente para fins acadêmicos no site da Marinha do Brasil (https://www.marinha.mil.br/chm/dados-do-segnav/cartasraster). Perfis a partir da linha de costa e equidistantes em 500m, totalizando 76 medidas, foram construídos e analisados em software GIS.

Após todas as variáveis especializadas, a classificação é feita de forma linearizada em ordem de incremento da vulnerabilidade em relação a subida do nível do mar e a erosão. É importante salientar que as variáveis quantitativas taxa de mobilidade costeira e distância até a isóbata de $20 \mathrm{~m}$ tiveram seus resultados separados em 5 grupos de forma linear para a classificação de vulnerabilidade entre muito baixa, baixa, moderada, alta e muito alta, como mostra a Tabela 2.

Tabela 2: Dados correspondentes às variáveis utilizadas no presente estudo. Intervalos dessas variáveis foram propostos para a área de estudo.

\begin{tabular}{|c|c|c|c|c|}
\hline $\begin{array}{l}\text { Vulnerabilidade - } \\
\text { Variáveis }\end{array}$ & Altimetria & $\begin{array}{l}\text { Geomorfologia } \\
\text { costeira }\end{array}$ & $\begin{array}{l}\text { Mobilidade costeira } \\
\text { (m/ano) }\end{array}$ & $\begin{array}{c}\text { Distância até a } \\
\text { isóbata de } 20 \mathrm{~m} \\
(\mathbf{k m})\end{array}$ \\
\hline $\begin{array}{c}1 \\
\text { Muito baixa }\end{array}$ & $\begin{array}{l}\text { Somente tabuleiro } \\
\text { costeiro }\end{array}$ & Costão rochoso & $\begin{array}{c}\text { Entre } 1,89 \\
( \pm 0,09) \mathrm{m} / \text { ano e } 2,56 \\
( \pm 0,09) \mathrm{m} / \mathrm{ano}\end{array}$ & $\begin{array}{c}\text { Entre } 34,9 \mathrm{~km} \mathrm{e} \\
39,1 \mathrm{~km}\end{array}$ \\
\hline$\stackrel{2}{\text { Baixa }}$ & $\begin{array}{l}\text { Tabuleiro costeiro } \\
\text { precedido por } \\
\text { estreita planície } \\
\text { costeira }\end{array}$ & - & $\begin{array}{c}\text { Entre } 1,09 \\
( \pm 0,09) \mathrm{m} / \text { ano e } 1,89 \\
( \pm 0,09) \mathrm{m} / \mathrm{ano}\end{array}$ & $\begin{array}{c}\text { Entre } 30,6 \mathrm{~km} \text { e } \\
34,9 \mathrm{~km}\end{array}$ \\
\hline $\begin{array}{c}3 \\
\text { Moderada }\end{array}$ & $\begin{array}{c}\text { Tabuleiro costeiro } \\
\text { com interseção de } \\
\text { vale }\end{array}$ & $\begin{array}{c}\text { Falésia do Grupo } \\
\text { Barreiras }\end{array}$ & $\begin{array}{c}\text { Entre } 0,36 \\
( \pm 0,09) \mathrm{m} / \text { ano e } 1,09 \\
( \pm 0,09) \mathrm{m} / \mathrm{ano}\end{array}$ & $\begin{array}{c}\text { Entre } 26,4 \mathrm{~km} \mathrm{e} \\
30,6 \mathrm{~km}\end{array}$ \\
\hline $\begin{array}{c}4 \\
\text { Alta }\end{array}$ & $\begin{array}{l}\text { Tabuleiro costeiro } \\
\text { com interseção de } \\
\text { vale, precedido por } \\
\text { estreita planície } \\
\text { costeira }\end{array}$ & $\begin{array}{l}\text { Planície costeira } \\
\text { estreita limitada por } \\
\text { falésia }\end{array}$ & $\begin{array}{c}\text { Entre }-0,36 \\
( \pm 0,09) \mathrm{m} / \text { ano e } 0,36 \\
( \pm 0,09) / \text { ano }\end{array}$ & $\begin{array}{c}\text { Entre } 22,1 \mathrm{~km} \mathrm{e} \\
26,4 \mathrm{~km}\end{array}$ \\
\hline $\begin{array}{c}5 \\
\text { Muito alta }\end{array}$ & $\begin{array}{l}\text { Somente planície } \\
\text { costeira }\end{array}$ & Planície costeira & $\begin{array}{c}\text { Entre }-1,09 \\
( \pm 0,09) \mathrm{m} / \text { ano e }-0,36 \\
\mathrm{~m} / \mathrm{ano}\end{array}$ & $\begin{array}{c}\text { Entre } 17,9 \mathrm{~km} \mathrm{e} \\
22,1 \mathrm{~km}\end{array}$ \\
\hline
\end{tabular}

\section{Resultados}

\subsection{Vulnerabilidade em função das diferentes variáveis}

\subsubsection{Geomorfologia Costeira}

O litoral da região sul do estado do Espírito Santo se mostra muito diversificada quanto as unidades geomorfológicas presentes e também ao grau de vulnerabilidade que cada uma das unidades apresenta. Sendo assim, 39\% do litoral foi classificado com vulnerabilidade muito alta, associada às planícies costeira adjacentes aos rios Itapemirim ao norte e Itabapoana ao sul. Em 40\% do litoral foi classificado com vulnerabilidade alta, associada a trechos do litoral com presença de estreita planície costeira limitada por falésias do Grupo Barreiras. Em 17\% do litoral foi classificado com vulnerabilidade moderada associada a trechos do litoral com presença falésias do Grupo Barreiras em atual estado erosivo. Por fim, em $4 \%$ do litoral foi classificado com vulnerabilidade muito baixa, associada aos trechos na região norte de do município de Marataízes onde o embasamento cristalino está atualmente em contato direto com o mar. 


\subsubsection{Altimetria}

O litoral é caracterizado por uma heterogeneidade de feições topográficas (Figura 4) e consequentemente diferentes graus de vulnerabilidade da costa frente às forçantes oceanográficas. Em $44 \%$ do litoral foi classificado com vulnerabilidade muito alta, associada aos terrenos formados por planícies costeiras quaternárias (Figura 5E), em sua maioria ao norte da área de estudo associada a desembocadura do Rio Itapemirim, e ao sul associada à desembocadura do Rio Itabapoana. Em 14\% do litoral foi classificado com vulnerabilidade alta, associado aos perfis topográficos que possuem a formação de tabuleiro costeiro com interseção de vale, precedido por planície costeira (Figura 5D). Apesar das áreas baixas de planícies costeiras e vales serem áreas de maior vulnerabilidade, os terrenos mais altos possuem uma vulnerabilidade menor. Essa classificação ocorre em áreas onde o Grupo Barreiras é precedido por estreitas planícies costeiras quaternárias e os perfis topográficos interceptam algum vale presente no Grupo Barreiras. Em 6\% do litoral foi classificado com vulnerabilidade moderada, onde os perfis identificaram o Grupo Barreiras diretamente em contato com o mar na forma de falésias vivas, e ainda que esses perfis interceptavam algum vale (Figura 5C). Em 31\% do litoral foi classificado com vulnerabilidade baixa, onde os perfis são compostos apenas pelo Grupo Barreiras precedido por estreita planície costeira e sem interseção de nenhum vale (Figura 5B), nessas regiões a vulnerabilidade é maior apenas para as estreitas planícies quaternárias, visto que as porções mais altas do Grupo Barreiras possuem uma menor vulnerabilidade. Para finalizar, em $4 \%$ do litoral foi classificado com vulnerabilidade muito baixa, onde todo o perfil é composto por terrenos elevados do Grupo Barreiras, não sendo precedido por planície costeira e não interceptando nenhum vale (Figura 5A).

\subsubsection{Variação da linha de costa}

Assim como a elevação, a linha de costa apresenta muito heterogênica quanto ao seu comportamento e, consequentemente apresenta diferentes graus de vulnerabilidade. Em $6 \%$ do litoral foi classificado com vulnerabilidade muito alta, com taxas de retrogradação da linha de costa entre 1,09 e 0,36 m/ano, na região do litoral onde se concentra as falésias que estão em atual estado erosivo. Em $41 \%$ do litoral foi classificado com vulnerabilidade alta, com taxas de variação da linha de costa entre $-0,36$ e $0,36 \mathrm{~m} / \mathrm{ano}$. Em $34 \%$ do litoral foi classificado com vulnerabilidade moderada, com taxas de progradação da linha de costa entre 0,36 e 1,09 m/ano. Em 14\% do litoral foi classificado com vulnerabilidade baixa, com taxas de progradação da linha de costa entre 1,09 e 1,89 m/ano. Para finalizar, em 5\% do litoral foi classificado com vulnerabilidade muito baixa, com taxas de progradação da linha de costa entre 1,89 e 2,56 m/ano, em regiões da planície costeira quaternária mais próximas a desembocadura do Rio Itabapoana.

\subsubsection{Distância da isóbata de $20 \mathrm{~m}$}

Para distância da isóbata de $20 \mathrm{~m}$ de profundidade (Figura 4), $20 \%$ do litoral foi classificado com vulnerabilidade muito alta com distâncias entre a linha de costa e a isóbata de $20 \mathrm{~m}$ de profundidade entre $17,9 \mathrm{~km}$ e $22,1 \mathrm{~km}$. Em $23 \%$ do litoral foi classificado com vulnerabilidade alta com distâncias entre $22,1 \mathrm{~km}$ e $26,4 \mathrm{~km}$. Em $16 \%$ do litoral foi classificado com vulnerabilidade moderada com distâncias entre $26,4 \mathrm{~km}$ e $30,6 \mathrm{~km}$. Em $31 \%$ do litoral foi classificado com vulnerabilidade baixa com distâncias entre 30,6km e $34,9 \mathrm{~km}$. E em $9 \%$ do litoral foi classificado com vulnerabilidade muito baixa com distâncias entre $34,9 \mathrm{~km}$ e $39,1 \mathrm{~km}$. 


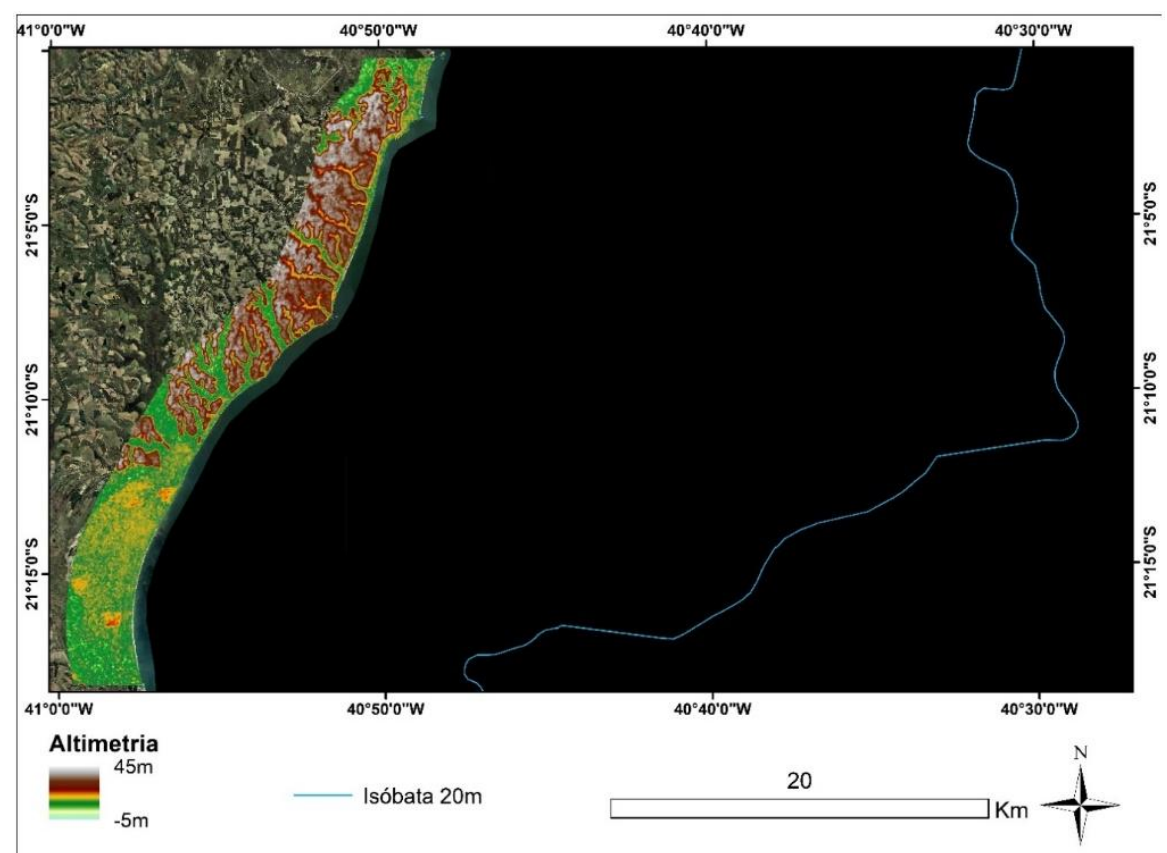

Figura 3: Mapa com destaque para o modelo digital de elevação criado a partir dos dados SRTM 30 e a isóbata de $20 \mathrm{~m}$ extraída a partir de carta náutica.

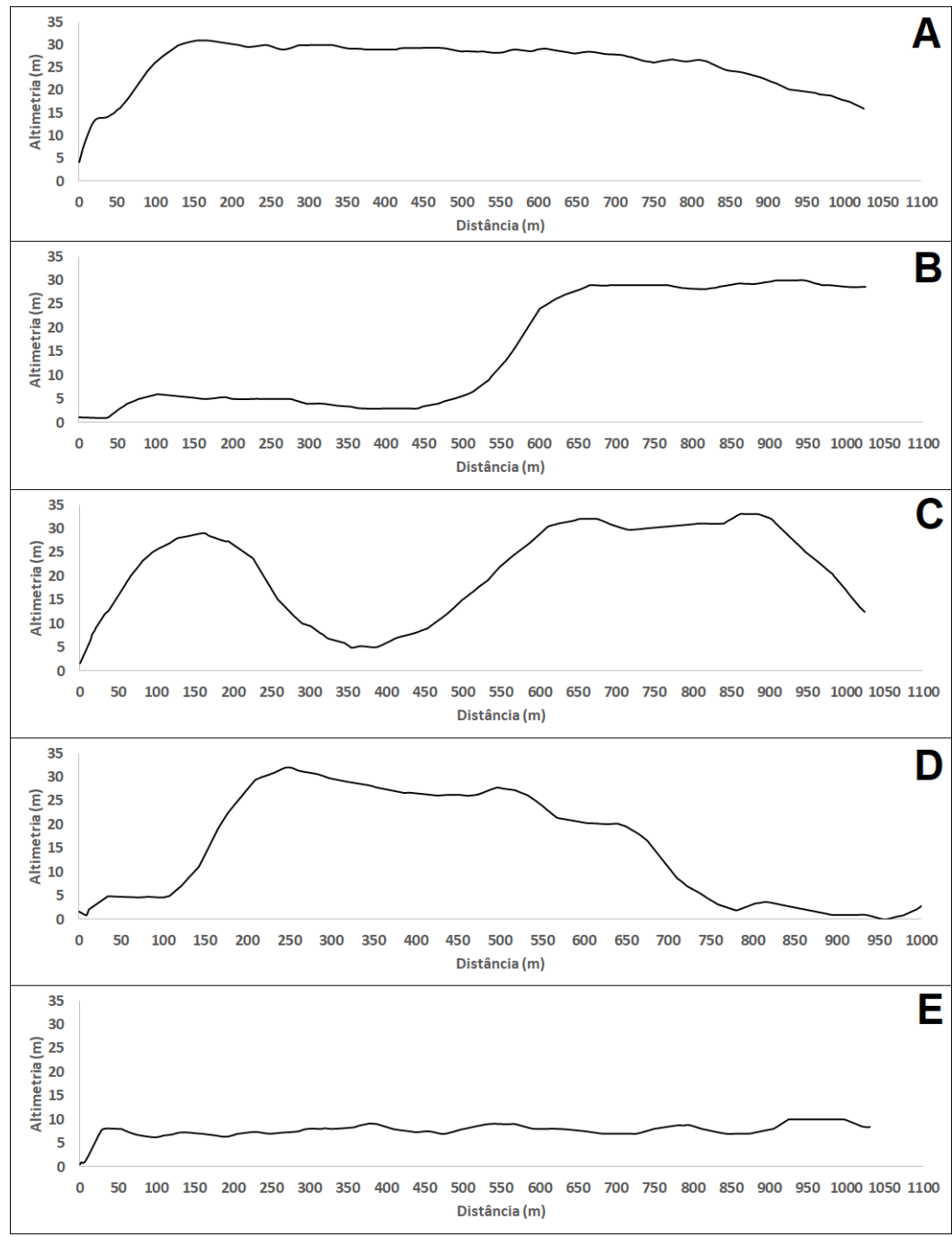

Figura 4: Exemplificação das 5 classes da variável altimetria. Sendo (A) Somente tabuleiro costeiro, (B) Tabuleiro costeiro precedido por estreita planície costeira, (C) Tabuleiro costeiro com interseção de vale, (D) Tabuleiro costeiro com interseção de vale, precedido por estreita planície costeira e (E) Somente planície costeira. 


\section{2 Índice de vulnerabilidade costeira}

Os valores de CVI calculados para a costa sul do estado do Espírito Santo variaram entre 1,41 e 11,18. Os percentis $20^{\circ}, 40^{\circ}, 60^{\circ}, 80^{\circ}$ foram respectivamente 3,36;5,32; 7,27 e 9,22. As classes do Índice de Vulnerabilidade Costeira foram classificadas como muito baixa $(<3,36)$, baixa $(3,36-5,32)$, moderada $(5,32$ $-7,27)$, alta $(7,27-9,22)$ e muito alta $(>9,22)$. A Figura 6 mostra a vulnerabilidade total da costa e também individualizada para cada indicador. O total da linha de costa do setor sul do estado do Espírito Santo, que apresenta cerca de $44 \mathrm{~km}$, é classificado com vulnerabilidade muito baixa em $9 \%$ do litoral, com vulnerabilidade baixa em $42 \%$ do litoral, com vulnerabilidade moderada em $25 \%$ do litoral, com vulnerabilidade alta em $12 \%$ do litoral, e com vulnerabilidade muito alta também em $12 \%$ do litoral.

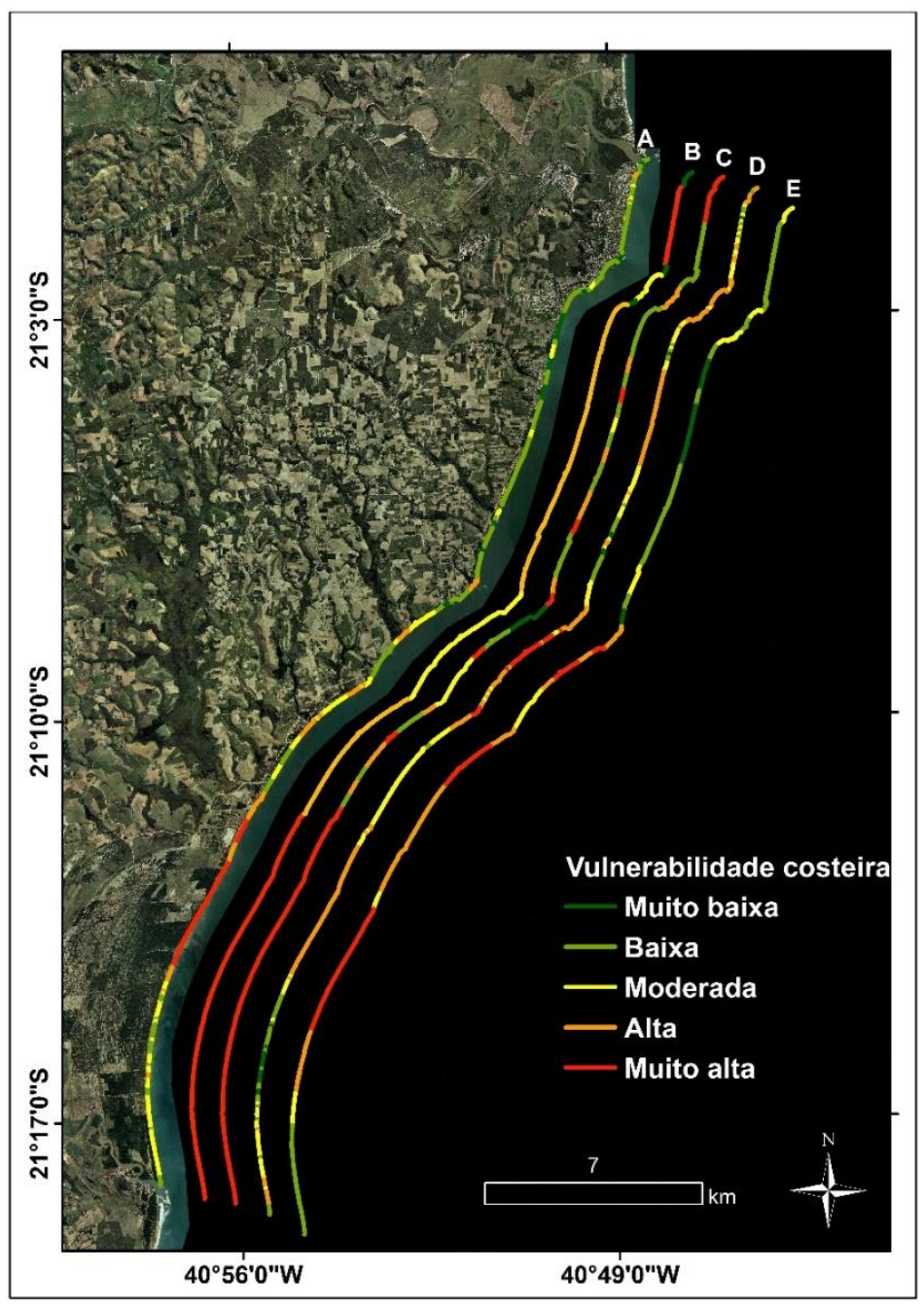

Figura 5: Sobre a linha de costa (A) CVI do litoral sul do Espírito Santo com magnitude de Muito baixa, Baixa, Moderada, Alta, e Muito alta. Note os quatro indicadores de vulnerabilidade utilizados, sendo (B) Geomorfologia, (C) Modelo digital de terreno, (D) Mobilidade costeira e (E) Distância da Isóbata de 20m.

\section{Discussão}

\section{1 Índice e variáveis}

Sem a influência da deposição fluvial e desenvolvimento das planícies fluviais dos rios Itapemirim e Itabapoana, o litoral é caracterizado por ter trechos em que os tabuleiros terciários do Grupo Barreiras estão presentes junto ao litoral. Essa feição ocorre sob a forma de falésias vivas que vivem um atual período de erosão por ação marinha, falésias mortas desenvolvidas em períodos de flutuações pretéritas do nível do mar e estreitas planícies quaternárias desenvolvidas na base dessas falésias; além de possuir em toda a plataforma interna a presença de terraços de abrasão, sendo feições que indicam presença de processos erosivos atuantes no litoral (ALBINO et al., 2001; ALBINO et al., 2006; ALBINO et al., 2016).

Com pouca contribuição de sedimento fluvial, o litoral é naturalmente vulnerável. As mudanças das forçantes meteoceanográficas, como o que acontece em passagens de sistemas frontais, no litoral que não possui uma faixa desenvolvida que permita grandes variações morfodinâmicas, é refletida diretamente sob 
formas negativas no litoral, com erosão das dunas frontais e dos depósitos terciários, e em regiões ocupadas colocando em risco residências, comércios e infraestrutura como ruas e calçadas a beira mar (ALBINO et al., 2001).

A geomorfologia demonstrou ser um dos melhores indicadores, onde as nas regiões em que se esperavam ser mais vulneráveis a erosão, a exemplo do segmento com presença de falésias; e a inundação, no segmento com extensas planícies costeiras com baixa altimetria, foram classificadas como sendo mais vulneráveis e isso refletiu no resultado final de forma satisfatória, semelhante aos resultados obtidos por Ozyurt e Ergin (2010), Yin et al. (2012), Hereher (2015), Loinenak e Hartoko (2015) e Pantusa et al. (2018).

A altimetria através dos perfis topográficos, analisou trechos do litoral que possuem mesma classificação quanto a vulnerabilidade da variável "geomorfologia costeira", mas que possam ser mais ou menos vulneráveis. Segundo Albino et al. (2010), as planícies quaternárias são classificadas como vulneráveis devido a intensa dinâmica e baixa altimetria, enquanto os terraços do Grupo Barreiras menos vulneráveis ao uso e ocupação. Contudo, segundo Teubner Junior et al. (2013), nas regiões de vales escavados do Grupo Barreiras, devido à baixa altimetria e à baixa permeabilidade do terreno, e ainda sendo assoreados por sedimentos quaternários, são as áreas mais vulneráveis à inundação, seja ela no período de chuvas ou por elevação do nível do mar.

Estudos vem mostrando que regiões costeiras baixas, associadas a desembocaduras fluviais, estão mais propensas a sofrerem com eventos episódicos de inundação, associados a eventos extremos, e ainda inundação permanente, forte erosão, perda de terreno, infiltração salina nos aquíferos e em estuários e danos a instalações e estruturas construídas pelo homem em decorrência da elevação do nível do mar (GORNITZ, 1991; NICHOLLS, 1995; MCLEAN et al., 2001; IPCC, 2007; YIN et al., 2012).

Por outro lado, regiões costeiras com presença de falésias estão mais propensas ao aumento do alcance das ondas e o ataque a base das falésias, consequentemente aumentando a frequência do ciclo de erosão das mesmas (EGUCHI; ALBINO, 2018). Esta situação salienta a vulnerabilidade erosiva das falésias, mesmo sendo áreas mais altas o processo erosivo representa perda permanente de terreno em comparação as regiões arenosas sem as presenças de falésias, que podem ser recuperadas ou reconstruídas naturalmente se ou quando as condições meteoceanográficas voltarem às passadas.

A altura de onda é proporcional a raiz quadrada da energia da mesma onda, e essa é a principal energia na mobilização e transporte de sedimentos costeiros, resultando na variação final entre erosão e deposição (GORNITZ, 1991, DWARAKISH et al. 2009, YIN et al., 2012). Segundo Padilla-Hernández e Monbaliu (2001) e Matos et al. (2014), existem diferentes mecanismos de dissipação de energia na interação das ondas com o fundo marinho, como percolação, fricção entre outros; e segundo Shemdin et al. (1978) o atrito com o fundo parece ser o principal deles em regiões costeiras arenosas. O estudo realizado por Trombetta et al. (2018) na plataforma continental sul do Brasil, analisou como uma declividade mais suave, comum em plataformas mais extensas, pode reduzir em até $98 \%$ da altura das ondas e aproximadamente $90 \%$ do potencial energético ao se aproximarem da costa, atenuando os efeitos erosivos causados pelas ondas na área litorânea.

A utilização da distância entre a costa e a isóbata de $20 \mathrm{~m}$ de profundidade, mostra os trechos da costa com maiores e menores potenciais de redução da energia das ondas ao se deslocarem sobre águas intermediárias e rasas e por fim atingirem a costa, e a variação do potencial de mobilização e transporte de sedimentos resultando de forma satisfatória na diferença de vulnerabilidade de diferentes trechos do litoral estudado.

Quanto à mobilidade da linha de costa, o referenciado pós-praia como indicador de linha de costa se mostrou eficiente em costas naturais, não artificializadas pelo processo de urbanização mostrando tendências de longo prazo na mobilidade natural da linha de costa e evitando falsas interpretações de curto e médio prazo, que segundo Muehe (2014) podem ser feitas com a utilização de outros indicadores. Porém, se mostrou ineficiente em locais onde a urbanização se deu por sobre áreas dinamizadas da praia, sendo um maquiador da mobilidade natural do sistema e o responsável por um comportamento de progradação ou estabilidade da costa onde se esperaria o comportamento natural de retrogradação do litoral.

O CVI para todo litoral estudado teve seu maior valor igual a 11,18 em um trecho sendo classificado em 3 variáveis com vulnerabilidade muito alta e em 1 como alta. Já o menor valor do CVI foi de 1,41 em um trecho sendo classificado em 2 variáveis com vulnerabilidade muito baixa, 1 variável com vulnerabilidade baixa e 1 como vulnerabilidade alta. Logo, mostra a eficiência das variáveis escolhidas em para a determinação da vulnerabilidade costeira da região e a eficiência do método em determinar a variabilidade da 
vulnerabilidade costeira ao longo é corroborada pelos estudos de Theiler e Hammar-Klose (2000), Pendleton et al. (2005), Kumar et al. (2010), Ozyurt e Ergin (2010), Yin et al. (2012), Hereher (2013), Hereher (2015), Loinenak e Hartoko (2015), Pantusa et al. (2018) e Serafim et al. (2018) realizado em países como Brasil, China, Egito, Estados Unidos, Índia, Indonésia, Itália e Turquia.

\subsection{Vulnerabilidade costeira do litoral sul capixaba}

O litoral de Marataízes e Presidente Kennedy é muito diverso em relação ao processo de urbanização, embora a distância entre ambos seja curta. Como já mencionado anteriormente Presidente Kennedy ainda possui o sistema costeiro regimentado pela interação dos sistemas marinho e fluvial, enquanto o processo de urbanização ocorrido em Marataízes prejudicou o balanço e transporte de sedimento causando erosão.

Não há solução única para esses problemas, e cada cidade deve fazer uma avaliação individual. Entretanto, a elevação do nível do mar traz o foco para a necessidade de estratégias de longo prazo no desenvolvimento das cidades, que deve ser integrado a outras preocupações como as de médio e curto prazo (NICHOLLS, 1995; NICHOLLS; LOWE, 2004).

Segundo Nicholls (1995), não fazer nada e a proteção reativa tem sido a principal resposta a problemas costeiros. No futuro, uma abordagem mais proativa deve ser incentivada. Enquanto medidas protetivas, em que obras de engenharia são feitas para proteger a infraestrutura costeira já existente, serão mais favorecidas em cidades, como já acontece em Marataízes; a acomodação e o retiro planejado podem ser adequados para algumas regiões, principalmente para áreas de futura urbanização costeira, como se enquadra fortemente o município de Presidente Kennedy. O objetivo principal deve ser antecipar potenciais problemas, antes que eles se desenvolvam e precisem de respostas apropriadas.

$\mathrm{O}$ afastamento de novas construções é um exemplo de mecanismo para realizar um retiro planejado. A distância adequada para o afastamento varia de região para região, e varia com as condições locais (NICHOLLS, 1995 e MMA, 2006).

A ocupação planejada em Presidente Kennedy, se torna ainda mais importante quando um megaempreendimento portuário está em fase de instalação num trecho de litoral que ainda não está urbanizado. O Porto Central é um complexo industrial portuário multipropósito de águas profundas em desenvolvimento numa área de aproximadamente 2.000 hectares. O Município de Presidente Kennedy designou uma área de 6.815 hectares ao redor do porto para ser desenvolvida como um distrito industrial, contribuindo para o crescimento planejado e integrado da região (PORTO CENTRAL, 2019).

Nicholls (1995) e Nicholls e Lowe (2004) recomendam um melhor conhecimento de base combinado com medidas proativas de baixo custo para a mudança climática, aplicadas de forma integrada em relação à problemática costeira. Sem uma abordagem integrada, considerando o médio e longo prazo, os impactos costeiros tendem a se tornar mais prováveis e frequentes, e as medidas reativas mais caras, ou ainda algumas áreas poderão até ser abandonadas. A elevação do nível do mar é um bom exemplo de preocupações costeiras de longo prazo, que precisam ser abordadas no planejamento costeiro das cidades (NICHOLLS, 1995).

\section{Conclusão}

O presente estudo analisou diversas feições e a classificação ocorreu com base nos estudos citados previamente, alterando a vulnerabilidade de algumas regiões, para que as gestões urbanas e costeiras deem as atenções devidas a essas localidades evitando prejuízos socioeconômicos e ambientais futuros.

Os resultados indicam que o conjunto de dados de sensoriamento remoto se mostrou eficaz em determinar a vulnerabilidade costeira da região estudada e adicionalmente ao CVI mostram a variabilidade ao longo do litoral da vulnerabilidade costeira, sendo a geomorfologia e altimetria as duas variáveis mais importantes no presente estudo, com a mobilidade costeira expondo potenciais tendências futuras e o grau de exposição ilustrando os hot spots de energia de ondas que chegam a costa.

A linha de pós praia como indicador da real posição da linha de costa se mostrou muito eficiente em costas naturais, não artificializadas pelo processo de urbanização mostrando tendências de longo prazo na mobilidade natural da linha de costa. E se mostrou ineficiente em locais onde a urbanização se deu por sobre áreas dinamizadas da praia, sendo o processo de ocupação e urbanização um maquiador da mobilidade natural do sistema. 
As soluções imediatistas são as mais utilizadas para lidar com questões climáticas e/ou ambientais nas regiões costeiras, e estas tendem a ser as soluções menos eficientes e traz a importância de que tais questões passem a ser analisadas sob a ótica de longo prazo pelas cidades, visto que os impactos costeiros tendem a se tornar mais frequentes e prováveis.

Estudos que busquem a análise e compreensão dos ambientes costeiros são necessários vistos os cenários previstos para o futuro em decorrência das mudanças climáticas e consequentemente elevação do nível dos oceanos, assim como o processo de desenvolvimento urbano e industrial, e podem ser realizados de forma expedita com dados de sensoriamento remoto disponíveis de forma gratuita, com resultados relevantes auxiliando a gestão costeira local.

\section{Agradecimento}

Pesquisa desenvolvida com o apoio financeiro Projeto CNPq Universal n. 421657/2016-2. O primeiro autor agradece a CAPES pela bolsa de mestrado. E os autores agradecem aos revisores anônimos pelas contribuições na melhoria do artigo.

\section{Referências}

ALBINO, J.; COELHO, A. L. N.; GIRARDI, G. NASCIMENTO, K. A. Espírito Santo IN: MUEHE, D. Panorama da erosão costeira no Brasil. Brasília: Ministério do Meio Ambiente; 2006.

ALBINO, J.; GHISOLFI, R. D.; TEIXEIRA, J. B.; BASTOS, A. C.; OLIVEIRA, L. A. K.; PASSOS, M. M.; CONTTI NETO, N. Vulnerabilidade Natural Costeira segundo critérios de Geologia, Geomorfologia e Oceanografia Física. Zoneamento Ecológico e Econômico do Espírito Santo. Costeiro. IEMA. UFLA, UFES, IJSN, 2010.

ALBINO, J.; CONTTI NETO, N.; OLIVEIRA, T.C.A. The beaches of Espírito Santo. In: SHORT, A.D., KLEIN A.H. da F. Brazilian Beach Systems. Volume 17. Coastal Research Library. Springer. 2016. P. 333362.

ALBINO, J.; PASOLINI, A.; MOURA, M. G. SARDENBERG, E. R.; COELHO, B. A. Erosão e estado morfodinâmico da praia central de Marataízes, sul do Espírito Santo. VI Simpósio Nacional de Geomorfologia. Geomorfologia Tropical e Subtropical: processos, métodos e técnicas. Goiânia, 2006.

ALBINO, J.; PAIVA, D. DE S. MODOLO, G. V. M. Geomorfologia, tipologia, vulnerabilidade erosiva e ocupação urbana das praias do litoral do Espirito Santo, Brasil. Geografares n.2, CCHN-UFES, Vitória. 2001.

ANFUSO, G.; DEL POZO, J. A. M. Assessment of Coastal Vulnerability Through the Use of GIS Tools in South Sicily (Italy). Environmental Management. V.43, 533 - 545, 2009. DOI: 10.1007/s00267-008-92388

ANTAQ. 2009. Subsídios técnicos para identificação de áreas destinadas à instalação de portos organizados ou autorização de terminais de uso privativo em apoio ao plano geral de outorgas. Relatório Final, Tomo 1. Maio/2019. Revisão 01.

ARAÚJO, R. S.; SILVA, G. V.; FREITAS, D.; KLEIN, A. H. F. Georreferenciamento de Fotografias Aéreas e Análise da Variação da Linha de Costa. In: Alcântara Carrió, J. (ed). Metodologías en Teledetección aplicada a la Prevención de Amenazas Naturales en el Litoral. Universidad Católica de Valencia, Espanha. 2008.

BIRD, E. C. F. Coastal geomorphology: an introduction. 2 ed. Wiley. 2008.

BOAK, E.H.; TURNER, I.L. Shoreline Definition and Detection: A Review. Journal of Coastal Research, 21(4), 688-703, 2005. ISSN 0749-0208.

BOATENG, I. GIS assessment of coastal vulnerability to climate change and coastal adaption planning in Vietnam. Journal of Coastal Conservation. 16, 25-36, 2012. DOI 10.1007/s11852-011-0165-0 
BONETTI, J. E.; WOODROFFE, C. D. Spatial Analysis on GIS for Coastal Vulnerability Assessment. In: BARTLETT, D. \& CELLIERS, L. (eds.). Geoinformatics for Marine and Coastal Management. Chapter 16. CRC Press, Boca Raton, p. 367-396. 2017. DOI: 10.1201/9781315181523-17

BURNINGHAM, H.; FRENCH, J. Understanding coastal change using shoreline trend analysis supported by cluster-based segmentation. Geomorphology. V.282, $131-149$, 2017. DOI: 10.1016/j.geomorph.2016.12.029

CHURCH, J.A., P.U. CLARK, A. CAZENAVE, J.M. GREGORY, S. JEVREJEVA, A. LEVERMANN, M.A. MERRIFIELD, G.A. MILNE, R.S. NEREM, P.D. NUNN, A.J. PAYNE, W.T. PFEFFER, D. STAMMER AND A.S. UNNIKRISHNAN, 2013: Sea Level Change. In: Climate Change 2013: The Physical Science Basis. Contribution of Working Group I to the Fifth Assessment Report of the Intergovernmental Panel on Climate Change [STOCKER, T.F., D. QIN, G.-K. PLATTNER, M. TIGNOR, S.K. ALLEN, J. BOSCHUNG, A. NAUELS, Y. XIA, V. BEX AND P.M. MIDGLEY (eds.)]. Cambridge University Press, Cambridge, United Kingdom and New York, NY, USA.

CONTTI NETO, N.; ALBINO, J.; COELHO, A. L. N. Geomorphology of Rio Itabapoana coastal plain (Espírito Santo, Brazil) and application to its vulnerability. In: XIII Congresso da Associação Brasileira de Estudos do Quaternário ABEQUA. 2011. Armação de Búzios.

DEVINE, N. P. Urban Vulnerability to Sea-Level Rise in the Third World. M.S. Thesis, Rutgers, The State University of New Jersey, New Brunswick, NJ 1992.

DWARAKISH, G. S.; VINAY, S. A.; NATESAN, U.; ASANO, T.; KAKINUMA, T.; VENKATARAMANA, K.; PAI, B. J.; BABITA, M. K. Coastal vulnerability assessment of the future sea level rise in Udupi coastal zone of Karnataka state, west coast of India. Ocean and Coastal Management. V.52, $467-478,2009$.

EGUCHI, B. M. M.; ALBINO, J. Bluff retreat by wave action on a tropical beach, In espírito santo, Brazil. Revista Brasileira de Geofísica. 36(4):569-580. 2018. ISSN 0102-261X.

ELFRINK, B.; ACETTA, D.; MANGOR, K. Innovative shoreline protection scheme for the city of Marataízes, Espírito Santo, Brazil. In: International Conference on Coastal Engineering. Clearware, Florida, USA, 2006.

GIRARDI, G.; COMETTI, R. DE S. Dinâmica do uso e ocupação do solo no litoral sul do estado do Espírito Santo, Brasil. Desenvolvimento e Meio Ambiente, n. 13, p. 51-73, 2006.

GORNITZ, V., Global coastal hazards from future sea level rise. Global Planetary Change. V.4, 379-398. 1991. DOI: 10.1016/0921-8181(91)90118-G

HEREHER, M. Coastal vulnerability assessment of Egypt's Mediterranean coast. Geomatics, Natural Hazards and Risk. V.6, 342-355. 2013 DOI:10.1080/19475705.2013.845115

HEREHER, M.E.. Assessment of South Sinai coastal vulnerability to climate change. Journal of Coastal Research, V.31(6), 1469-1477. 2015. ISSN 0749-0208.

IBGE - Instituto Brasileiro de Geografia e Estatística (2014). Produto Interno Bruto dos Municipios 2010 - 2014. Disponível em:

<https://ww2.ibge.gov.br/home/estatistica/economia/pibmunicipios/2014/default_xls.shtm>.

KLEIN, R.; NICHOLLS, R. Assessment of coastal vulnerability to climate change. Ambio. V.28(2), 182187. 1999.

KUMAR, T. S.; MAHENDRA, R. S.; NAYAK, S. RADHAKRISHNAN, K. SAHU, K. C. Coastal vulnerability assessment for Orissa State, East Coast of India. Journal of Coastal Research. V.26(3), 523534. 2010. DOI: $10.2112 / 09-1186.1$ 
LOINENAK, F.A.; HARTOKO, A.; MUSKAANANFOLA, M.R. Mapping of coastal vulnerability using the coastal vulnerability index and geographic information system. International Journal of Technology. V.5, 819-827. 2015. ISSN 2086-9614.

MARTIN, L;. SUGUIO, K.; FLEXOR, J. M.; ARCANJO, J. D. Coastal Quaternary formations of the southern part of the State of Espírito Santo (Brazil). Academia Brasileira de Ciências. V.68, 389-404. 1996.

MATOS, M.; DE F. A.; AMARO, V. E.; FORTES, C. J.; SCUDELARI, A. C. Interação entre ondas oceânicas e fundo marinho: Resultados na plataforma continental setentrional do Rio Grande do Norte. Revista Brasileira de Geomorfologia V.15, 371-391. 2014. ISSN 2236-5664.

MCLEAN, R.; TSYBAN, A.; BURKETT, V.; CODIGNOTTO, J. O.; FORBES, D. L.; MIMURA, N.; BEAMISH, R. J.; ITTEKKOT, V. Coastal zone and marine ecosystems. In: MCCARTHY, J. J. CANZIANI, O. F. LEARY, N. A. DOKKEN, D. J. WHITE, K. S. (Eds.), Climate Change 2001: Impacts, Adaptation and Vulnerability. Cambridge University Press, Cambridge, pp.343-380. 2001.

MMA. Projeto orla: fundamentos para gestão integrada. Ministério do Meio Ambiente, Ministério do Planejamento, Orçamento e Gestão. - Brasília: MMA, 74 p. 2006.

MUEHE, D.; OLIVEIRA, L. K. Deslocamento da linha de costa versus mobilidade praial. Quaternary and Environmental Geosciences. V.05(2), 121-124. 2014.

NICHOLLS, R. J. Coastal megacities and climate change. Geojournal. V.37(3), 369-379. 1995.

NICHOLLS, R. J.; LOWE, J. A. Benefits of mitigation of climate change for coastal areas. Global Environmental Change. V.14(3), 229-244. 2004. DOI: 10.1016/j.gloenvcha.2004.04.005

OZYURT, G.; ERGIN, A. Improving coastal vulnerability assessments to sea-level rise: a new indicatorbased methodology for decision makers. Journal of Coastal Research. V.26(2), 265-273. 2010. DOI: $10.2112 / 08-1055.1$

PADILHA-HERNÁNDEZ, R.; MONBALIU, J. Energy balance of wind waves as a function of the bottom friction formulation. Coastal Engineering. V.43, 131-148, 2001. DOI: 10.1016/S0378-3839(01)00010-2

PANTUSA, D.; D'ALESSANDRO, F.; RIEFOLO, L.; PRINCIPATO, F.; TOMASICCHIO, G. R. Aplication of a coastal Vulnerability Index. A case study along the Apulian coastline, Italy. Water. V.10(9):1218. 2018. DOI: 10.3390/w10091218

PENDLETON, E.A.; THIELER, E.R.; AND WILLIAMS, S.J. Coastal Vulnerability Assessment of Golden Gate National Recreation Area to Sea-Level Rise. U.S. Geological Survey Open-File Report 2005-1058 p.27.

PORTO CENTRAL, 2018. Disponível em: 〈http://www.portocentral.com.br〉. Acesso em: 15 de agosto de 2018.

RAMIERI, E.; HARTLEY, A.; BARBANTI, A.; SANTOS, F. D.; GOMES, A.; HILDEN, M.; LAIHONEN, P.; MARINOVA, N. E.; SANTINI, M. Methods for assessing coastal vulnerability to climate change. ETC CCA Technical Paper 1/2011. European Topic Centre on Climate Change Impacts, Vulnerability and Adaptation, Bologna, Italy. 2011.

SANDERS, B. F. Evaluation of on-line DEMs for flood inundation modeling. Advances in Water Resources. V.30:1831-1843. 2007. DOI: 10.1016/j.advwatres.2007.02.005.

SERAFIM, M. B.; SIEGLE, E.; CORSI, A. C.; BONETTI, J. Coastal vulnerability to wave impacts using a multi-criteria index: Santa Catarina (Brazil). Journal of Enrivonment Management. V.230, 21-32. 2019. DOI: 10.1016/j.jenvman.2018.09.052. 
SHARPLES, C.; MOUNT, R.; PEDERSEN, T.; LACEY, M. NEWTON, J.; JASKIERNIAK, D.; WALLACE, L. The Australian coastal smartline geomorphic and stability map version 1: project report. Prepared for Geoscience Australia and the Department of Climate Change by the School of Geography and Environmental Studies, University of Tasmania, 2009. Hobart.

SHEMDIN, O.; HASSELMANN, K.; HSIAO, S. V.; HERTERICH, K. Nonlinear and Linear Bottom Interaction Effects in Shallow Water. In: FAVRE, A. HASSELMANN, K. (eds) Turbulent Fluxes Through the Sea Surface, Wave Dynamics, and Prediction. Springer, Boston, 1978, MA.

TAUBNER JUNIOR, F. J.; LIMA, V. S.; FILETI, R. B.; ZACCHÉ, V. B.; ALBINO, J. Mapeamento Geomorfológico e Vulnerabilidade à Inundação de uma Vila Costeira no Espírito Santo. XV Simpósio Brasileiro de Geografia Física Aplicada. Uso e Ocupação da Terra e as Mudanças das Paisagens. Vitória, 2013.

THIELER, E. R.; HAMMAR-KLOSE, E. S. National assessment of coastal vulnerability to future sea-level rise: preliminary results for the U.S. Atlantic coast. U.S. Geological Survey, Open File Report. 99-593, 2000. 1 sheet.

THIELER, E.R.; HIMMELSTOSS, E.A.; ZICHICHI, J.L.; MILLER, T.L. Digital shoreline analysis system (DSAS) version 3.0: An ArcGIS extension for calculationg shoreline change: U.S. Geological Survey Open-file Report. 2005.

TROMBETTA, T. B.; OLEINI, P. H.; LOPES, B. V.; GUIMARÃES, R. C.; MARQUES, W. C.; ISOLDI, L. A. Atenuação da Energia das Ondas sobre uma Rampa que atua como Estrutura de Proteção Costeira na Plataforma Sul do Brasil. Revista Brasileira de Geografia Física. v.11, n.04 (2018) 1303-1320. DOI: 10.26848/rbgf.v11.4.p1303-1320

YIN, J.; YIN, Z.; WANG J.; XU, S.National assessment of coastal vulnerability to sea-level rise for the Chinese coast. Journal of Coastal Conservation. V.16(1):123-133. 2012. DOI: 10.1007/s11852-0120180-9.

WOODROFFE, C. D. Coasts: Form, Process, and Evolution. Cambridge University Press, Cambridge, UK, 2002.

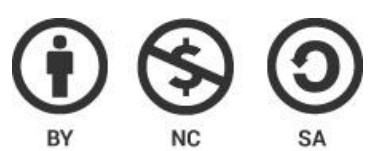

